\title{
Effect of Ti-doping and Octahedral Morphology on Electrochemical Performance of Lithium Manganate Oxide as Cathode Materials for LIBs
}

Yongfeng $\mathrm{Li}^{1}$, Gan Zhu ${ }^{1}$, Qiwen Ran ${ }^{2, *}$, Jintao Liu ${ }^{2}$, Yu Zhou ${ }^{1}$, Mengyuan Zhao ${ }^{1}$, Peng Cao ${ }^{2}$, Hongyuan Zhao ${ }^{1, *}$

${ }^{1}$ Research Center for Advanced Materials and Electrochemical Technology, Henan Institute of Science and Technology, Xinxiang, 453003, China

${ }^{2}$ School of Materials and Energy, University of Electronic Science and Technology of China, Chengdu 610054, China

${ }^{3}$ Department of Chemical and Materials Engineering, The University of Auckland, Private Bag 92019, Auckland, 1142, New Zealand

*E-mail: qiwenran@yeah.net (Q. Ran), hongyuanzhao@126.com (H. Zhao)

Received: 2 June 2021 / Accepted: 20 July 2021 / Published: 10 August 2021

This work proposed a collaborative strategy of Ti-doping and octahedral morphology to improve the cycling property of lithium manganate oxide $\left(\mathrm{LiMn}_{2} \mathrm{O}_{4}\right)$. The $\mathrm{LiTi}_{0.05} \mathrm{Mn}_{1.95} \mathrm{O}_{4}$ octahedrons were prepared by solid-phase method with $\mathrm{Mn}_{3} \mathrm{O}_{4}$ octahedrons and $\mathrm{TiO}_{2}$ nanoparticles as manganese precursor and titanium dopant, respectively. XRD and SEM characterizations indicated that the existence of tetravalent titanium ions presents no substantive impact on the spinel structure. The obtained $\mathrm{LiTi}_{0.05} \mathrm{Mn}_{1.95} \mathrm{O}_{4}$ sample well inherited the octahedral morphology of $\mathrm{Mn}_{3} \mathrm{O}_{4}$ octahedrons. For this sample, the Ti-doping could enhance the crystal structure stability and avoid the reduction of trivalent manganese ions, and the octahedral morphology helped to maintain the spinel structure by inhibiting the manganese dissolution. These functions could effectively enhance the cycling stability of $\mathrm{LiMn}_{2} \mathrm{O}_{4}$. When tested at $1.0 \mathrm{C}$, the 1 st reversible capacity of $\mathrm{LiTi}_{0.05} \mathrm{Mn}_{1.95} \mathrm{O}_{4}$ octahedrons was higher than that of both the $\mathrm{LiTi}_{0.05} \mathrm{Mn}_{1.95} \mathrm{O}_{4}$ particles and $\mathrm{LiMn}_{2} \mathrm{O}_{4}$ particles. After 100 cycles, the capacity retention of $\mathrm{LiTi}_{0.05} \mathrm{Mn}_{1.95} \mathrm{O}_{4}$ octahedrons could reach up to $94.2 \%$, which was much higher than that of other two samples $(90.3 \%$ and $75.2 \%)$. Furthermore, the high-rate capability and high-temperature performance were significantly improved due to the synergetic modification of Ti-doping and octahedral morphology.

Keywords: Lithium manganate; Titanium doping; Octahedral morphology; Cycling stability; Synergistic effect

\section{$\underline{\text { FULL TEXT }}$}

(C) 2021 The Authors. Published by ESG (www.electrochemsci.org). This article is an open access article distributed under the terms and conditions of the Creative Commons Attribution license (http://creativecommons.org/licenses/by/4.0/). 